\title{
Elevated glycated haemoglobin in non-diabetic patients is associated with an increased mortality in myocardial infarction
}

\author{
T A Chowdhury, S S Lasker
}

\begin{abstract}
Summary
Diabetes is associated with increased mortality following acute myocardial infarction compared to the general population. Elevated glycated haemoglobin $\left(\mathrm{HbA}_{1 \mathrm{c}}\right)$ in diabetic patients is also associated with increased mortality following acute myocardial infarction, while mild elevations in $\mathbf{H b A}_{\mathrm{c}}$ are associated with impaired glucose tolerance. The aim of this study was to determine the influence of $\mathbf{H b A}_{1 \mathrm{c}}$ on outcome of acute myocardial infarction in 253 non-diabetic patients, 46 of whom died in one year. In univariate analysis, risk factors for death included smoking, glucose, cholesterol and $\mathrm{HbA}_{1 \mathrm{c}}$. In logistic regression analysis $\mathbf{H b A}_{\mathrm{ic}}$ was an independent risk factor for death. Over one-third of the fatality group had an $\mathrm{HbA}_{1 \mathrm{c}}$ in the highest quartile, compared to one-fifth of the surviving group $(p=0.02)$. Elevated $\mathrm{HbA}_{1 \mathrm{c}}$ is a risk marker for shortterm mortality following acute myocardial infarction in non-diabetic subjects.
\end{abstract}

Keywords: glycated haemoglobin; myocardial infarction; mortality

Patients with diabetes mellitus have a poorer outcome after acute myocardial infarction (AMI) than the general population. ${ }^{1}$ Cardiovascular mortality is also increased in subjects with impaired glucose tolerance. ${ }^{2}$ Hyperglycaemia is common during AMI, and may be a result of stress-induced catecholamine release or previously unidentified diabetes mellitus. Glycated haemoglobin $\left(\mathrm{HbA}_{1 c}\right)$ is a measure of glycaemia over the preceding months, and may be helpful in detecting abnormalities of glucose tolerance as there is an inverse relationship between $\mathrm{HbA}_{\mathrm{lc}}$ and glucose tolerance. ${ }^{3} \mathrm{El}-$ evated $\mathrm{HbA}_{\mathrm{lc}}$ levels are associated with an increased mortality following AMI in diabetic patients. ${ }^{4}$ The aim of this study was to determine whether $\mathrm{HbA}_{1 \mathrm{c}}$ levels at presentation of AMI had an influence on the short-term outcome in non-diabetic subjects.

Department of

Medicine, Queen

Elizabeth Hospital, Birmingham,

B15 2TH, UK

T A Chowdhury

S S Lasker

Accepted 16 December 1997 admitted to three hospital coronary care units with their first AMI over the period January to December 1995 were studied. Patients with a random blood glucose of $>11.1 \mathrm{mmol} / 1$ were excluded. Those with random blood glucose on admission between $7.8-11.1 \mathrm{mmol} / \mathrm{l}$ underwent a standard 75-g oral glucose tolerance test prior to discharge, and were excluded from the analysis if $2-$ hour glucose was $>11.1 \mathrm{mmol} / 1$. AMI was defined as a history of chest pain with evolving changes on the electrocardiogram diagnostic of AMI (ST elevation or T-wave inversion) with elevation in serial creatine kinase levels. Plasma for $\mathrm{HbA}_{\mathrm{lc}}$ was taken at admission, and measured in a central laboratory (normal range 3.5-6.5\%). All patients were given thrombolysis unless contraindicated. Clinical evidence of heart failure (radiographic evidence of pulmonary venous congestion, basal crackles or presence of a third heart sound) was treated with the introduction of an angiotensin-converting enzyme (ACE) inhibitor. Cholesterol $>6.5 \mathrm{mmol} / \mathrm{l}$ was treated with a statin. Surviving patients were re-assessed one year later in early 1997, and causes of death for the fatalities were established from hospital or general practice records and patients' relatives. Statistical differences in characteristics between survivors and fatalities over one year follow-up was assessed using the Students' $t$-test for parametric data and the MannWhitney U-test for non-parametric data with significance achieved at $p<0.05$. Stepwise logistic regression analysis was undertaken using all the variables associated with relapse in the univariate analysis using the statistical software, Minitab. The $\mathrm{R}^{2}$ value was adjusted according to the number of variables introduced into the model.

\section{Results}

A total of 301 patients with AMI and no previous history of diabetes were studied, of whom 21 were excluded due to a random blood glucose $>11.1 \mathrm{mmol} / 1$. A total of 58 patients had a random blood glucose between 7.8-11.1 $\mathrm{mmol} / \mathrm{l}$, and underwent a standard $75-\mathrm{g}$ oral glucose tolerance test. Almost half (27) of these subjects had a 2-hour blood glucose of $>11.1$ $\mathrm{mmol} / \mathrm{l}$, and hence were diabetic, while 16 (27.6\%) had evidence of impaired glucose tolerance (2-hour blood glucose 7.8-11.1 $\mathrm{mmol} / \mathrm{l}$ ), although they were not excluded from subsequent analysis. Thus, 48 patients were excluded due to newly diagnosed diabetes. Clinical characteristics of the 253 non-diabetic subjects are shown in table 1 . 
Table 1 Clinical characteristics of fatalities and survivors of AMI

\begin{tabular}{|c|c|c|}
\hline & Dead & Alive \\
\hline$n$ & 46 & 207 \\
\hline Mean age (years) & $63.2(\mathrm{SD} 6.3)$ & 64.0 ( SD 5.9) \\
\hline Male sex & $28(60.6)$ & $124(58.4)$ \\
\hline Smokers ${ }^{\star}$ & $18(39)$ & $73(34.2)$ \\
\hline Median plasma glucose $(\mathrm{mmol} / \mathrm{l}) \dagger$ & 6.9 & 5.3 \\
\hline Impaired glucose tolerance ${ }^{\star}$ & $6(13)$ & $10(4.8)$ \\
\hline Median diastolic blood pressure $(\mathrm{mmHg})$ & 90 & 90 \\
\hline Median systolic blood pressure ( $\mathrm{mmHg}$ ) & 150 & 150 \\
\hline Median cholesterol $(\mathrm{mmol} / \mathrm{l}) \dagger$ & 5.7 & 5.3 \\
\hline ACE inhibitor ${ }^{\star}$ & $12(26)$ & $36(17.4)$ \\
\hline Aspirin & $42(96)$ & $201(97)$ \\
\hline Beta blocker & $14(30)$ & $66(31.9)$ \\
\hline Median $\mathrm{HbA}_{\mathrm{lc}}(\%) \dagger$ & 5.9 & 4.3 \\
\hline
\end{tabular}

Data are $n(\%)$ unless otherwise stated; ${ }^{*} \mathrm{p}<0.01 ; \mathrm{tp}<0.001$

Table 2 Fatalities and survivors of acute myocardial infarction divided into quartiles of $\mathrm{HbA}_{\mathrm{lc}}$

\begin{tabular}{lllll}
\hline$H b A_{l c}$ & $<4.0$ & $4.1-5.2$ & $5.2-6.0$ & $>6.1$ \\
\hline Dead & $5(10.8)$ & $10(21.7)$ & $14(30.4)$ & $17(36.9)$ \\
Alive & $59(28.5)$ & $56(27.0)$ & $49(23.7)$ & $43(20.8)$ \\
\hline
\end{tabular}

Data are $n(\%), \chi^{2}=9.881, p=0.02$.

In total, 46 deaths occurred within one year from AMI, 19 of these within the first month. No significant difference was seen in the age, sex and ethnic distribution of the survivors and fatalities. The two groups had similar blood pressures and proportion on aspirin and $\beta$-blockers. Significant heterogeneity between the survivors and fatalities was seen in smoking status, plasma glucose, proportion with impaired glucose tolerance, serum cholesterol, proportion on an ACE inhibitor and $\mathrm{HbA}_{\mathrm{ic}}$. Dividing $\mathrm{HbA}_{\mathrm{lc}}$ into quartiles (table 2), a significantly higher proportion of patients who died within one year of AMI had an $\mathrm{HbA}_{1 \mathrm{c}}$ in the highest quartile $\left(\chi^{2}=9.881, p=0.02\right)$. In stepwise logistic regression analysis, introducing all variables showing a significant association with fatality from AMI in univariate analysis, $\mathrm{HbA}_{1 \mathrm{c}}$ was an independent risk factor for death (odds ratio $\left[\mathrm{HbA}_{\mathrm{lc}}>6.1\right] /\left[\mathrm{HbA}_{\mathrm{lc}}\right.$ $<5.2]=2.36(95 \%$ confidence intervals $1.65-$ 4.23), $\mathrm{p}<0.001)$.

\section{Discussion}

Elevated $\mathrm{HbA}_{\mathrm{ic}}$ was found to be associated with an increased mortality in non-diabetic subjects suffering an AMI. Although the fatality group had a higher proportion of subjects with other risk factors associated with poorer

1 Abbud Z, Shindler D, Wilson A, Kostis J. Effect of diabetes mellitus on short and long term mortality rates after myocardial infarction of modest extent in patients with diabetes mellitus. Am Heart $\mathcal{f}$ 1984;108:31-7.

2 Fuller JH, Shipley MJ, Rose G, Jarrett RJ, Keen $\mathbf{H}$. Coronary heart disease and impaired glucose tolerance. The Whitehall study. Lancet 1980;i:1373-6.

3 Lev-Ran A, Vanderlaan WP. Glycohemoglobins and glucose tolerance. $\Im A M A$ 1979;241:912-4.

4 Yudkin JS, Oswald GA, McKeigue PM, Forrest RD, Jackson CA. The relationship of hospital admission and fatality from myocardial infarction to glycohaemoglobin levels. Diabetologia 1988;31:201-5.

\section{Summary points}

- diabetes mellitus is associated with a higher mortality following myocardial infarction

- hyperglycaemia is common during myocardial infarction and may not indicate the presence of diabetes mellitus

- poorer glycaemic control in diabetic subjects is associated with a higher mortality following myocardial infarction

- in non-diabetic subjects, higher $\mathrm{HbA}_{1 \mathrm{c}}$ levels and impaired glucose tolerance are independent risk factors for mortality following myocardial infarction

- $\mathrm{HbA}_{\mathrm{ic}}$ may be a useful risk marker for mortality after myocardial infarction in non-diabetic subjects

prognosis after AMI (smokers, higher cholesterol), $\mathrm{HbA}_{\mathrm{cc}}$ remained an independent risk factor for death. One-third of subjects dying from an AMI within one year had an $\mathrm{HbA}_{1 \mathrm{c}}$ in the highest quartile, compared to only one-fifth of the surviving group. The present study confirms previous observations in diabetic subjects suggesting that higher glucose levels during AMI are associated with increased mortality. ${ }^{5}$ The reason for this phenomenon is unclear, although elevated plasma glucose in the context of AMI may be due to stress-induced catecholamine release. Thus, larger infarcts may be associated with greater release of catecholamines, and hence higher random blood glucose levels. ${ }^{6}$

Whilst it is well established that diabetes mellitus confers a greater risk of death following AMI, it has not been fully established whether impaired glucose tolerance also predicts a poorer outcome. In our study, a greater proportion of patients who died within one year of AMI had impaired glucose tolerance ( $13 \%$ vs $4.8 \%)$. Excess risk of AMI is seen in subjects with impaired glucose tolerance, ${ }^{2}$ and aggressive treatment of hyperglycaemia during AMI has been shown to reduce mortality in diabetic subjects. ${ }^{7}$ The mechanism by which impaired glucose tolerance may influence mortality after AMI is unclear, but its association with the metabolic syndrome (syndrome $\mathrm{X})$ may explain this excess mortality. ${ }^{8}$ Thus, patients with mild increases in $\mathrm{HbA}_{1 \mathrm{c}}$ may have other metabolic or genetic factors which confer greater coronary risk.

5 Sewardsen M, Vythilingum S, Jailal I, Becker PJ. Prognostic importance of admission plasma glucose in diabetic and non-diabetic patients with acute myocardial infarction. $Q \mathcal{F}$ Med 1989;265:461-6.

6 Gwilt DJ, Petri M, Lewis PW, Nattrass M, Pentecost BL. Myocardial infarct size and mortality in diabetic patients. $B r$ Heart $\mathcal{F}$ 1985;54:466-72.

7 DIGAMI Study Group. Prospective randomised study of intensive insulin treatment on long term survival after acute myocardial infarction in patients with diabetes mellitus. $B M \mathcal{F} 1997 ; 317: 1512-5$.

8 Davies MJ, Rayman G, Day JL. Increased cardiovascular mortality in subjects with impaired glucose tolerance: link with lipoprotein (a). BMf 1992;304:1610-1. 